\title{
ECOLOGY AND SPATIAL ANALYSIS
}

\author{
JAMES D. CLARKSON
}

\begin{abstract}
Placing an ecological approach in the general framework of American geographic thought indicates the usefulness of distinguishing two trends in the development of this thought-the one ecological, the other spatial. American geography tended to reject the ecological approach because it was identified at an early period with environmental determinism. A spatial, non-functional, approach became dominant. Although the two approaches are two ends of a continuum, and thus connected, they arise from and lead to different sets of questions which involve different approaches and different bodies of theory. The ecological approach may be divided into four imprecise types-biological, human, cultural, and urban-political. The cultural-ecological approach is particularly useful in analyzing obstacles to innovation acceptance in agricultural development because it emphasizes the analysis of existent systems from different viewpoints. Four sets of reality, or viewpoints, can be distinguished in this context-that of the scientist-observer, that of the change-agent, that of the cultivator, and that of the ideal-set of the cultivator. Only when the overlaps and conflicts of these sets are recognized can a realistic appraisal be made. This is only a single instance of the potential of an ecological approach. Spatial theory and ecological theory have not yet been joined. The evident usefulness of both indicates the importance of attempting such a joining, and the futility of arguing for the ascendance of one over the other.
\end{abstract}

$E^{\mathrm{N}}$ NORMOUS problems of economic development face most of the nations which have won independence since World War II; even countries with longer histories of self-rule are troubled. The West, which in the past has borrowed much from other parts of the world, is now in a position to repay part of its debt by contributing some of its science and technology towards solving these developmental problems. For this coin to pass as payment, however, it must be changed into the international currency of mutual understanding, which requires some adjustment in the thinking of all the parties concerned. This paper sets forth an approach towards one part of economic development, the process of innovation acceptance. It especially deals with agricultural innovation, which reflects the interests of the author, rather than methodological constraints inherent in the approach. Because the mode and model of the research advocated is felt to be an integral part of certain forms of geographic study, the first part of the paper is devoted to placing the

Accepted for publication June 27, 1969.

Dr. Clarkson is Assistant Professor of Geography at the University of Michigan at Ann Arbor. arguments in a perspective of the development of geographic thought. ${ }^{1}$

Attempts to categorize developments in a discipline become more difficult as we move forward in time towards our own period, and for this reason it is useful to cast back to earlier periods to distinguish the threads we hope to follow. This is not to argue that a discipline must be what it has always been, but rather to point up the fact that the present did, after all, evolve from something and did not spring full-blown from the heads of our contemporaries. One purpose of this paper is to identify two trends, or channels, in the development of American geography, the one to be called spatial analysis and the other ecologic analysis. In many instances and times the distinction is hazy, for these two modes of thought frequently have been intertwined. Nor is it

${ }^{1}$ An earlier version of this paper was circulated as Ecologic and Spatial Analysis: Towards Adaptive Research in the Developing Countries, Working Paper No. 7, Social Science Research Institute, (Honolvlu: University of Hawaii). The author particularly wishes to thank O. D. Duncan, R. W. Kates, R. P. Moss, G. Olsson, A. Pred, P. Siegel, and W. L. Thomas, Jr., for their comments on that working draft. 
suggested that these two types of analysis cover all geographic research. Rather, it is argued that this dichotomy helps clarify relationships between types of research which often seem unrelated and, obversely, that work which may seem related can be seen to be unrelated.

A potentially fruitful area of research in which ecological and spatial analysis are brought to bear on a common problem is in the study of innovation diffusion and acceptance. If we accept the terminology of this paper, then innovation diffusion has been the object of investigation by geographers interested in spatial analysis (excepting, for the moment, the work of Sauer and others of the Berkeley school). One argument of this paper is that innovation acceptance is a concern of those interested in ecological analysis. It may be legitimately argued that it is difficult, if not impossible, for a single individual to be competent in both modes of research, but this surely does not suggest that one is somehow more "geographic" than the other.

Innovation diffusion studies, however, which deal with problems of agricultural development have been mostly the work of non-geographers. Yet, the place for the geographer has seldom been clearer: ${ }^{2}$

There is a sparsity of reported studies in which scientists have tried to measure the rate or extent of practice-adoption (in relation to the technical adequacy of the change agent) or the technical appropriateness of the practice advocated.

The second part of the paper will consider the different uses of the term "ecology" currently found in the literature of several social and natural sciences. Four broad classes of this usage will be distinguished, albeit imprecisely. These are biologic, human, cultural, and urban-and-political. Here again class boundaries will be seen to be indistinct at times, but the classification is held to be analytically useful nonetheless.

${ }^{2}$ F. C. Byrnes, Some Missing Variables in Diffusion Research and Innovation Strategy, (New York: Agricultural Development Council, Reprint, 1968), p. I. While this does not exhaust the possibilities of an ecologic approach, it is well within the class of research advocated here. The classical diffusion study, recently made available in English, is $T$. Hägerstrand, Innovation Diffusion as a Spatial Process, translated by A. Pred and G. Haag (Chicago: University of Chicago Press, 1967).
The view that geography has an ecological component is by no means a new one. Indeed, some have argued that geography is or should be all ecologic. H. H. Barrows' paper, which is discussed below, is perhaps the best-known to American geographers. ${ }^{3}$ The argument put forth here is definitely not that geography is or should be all ecologic. The justification for re-emphasizing the ecologic approach is based on two felt needs:

1) Previous geographic writings on ccology have either discussed the subject in general terms only, or have emphasized or defined a single ecologic approach. This paper attempts to distinguish different analytic approaches; all are ecologic.

2) Writings on ecology are frequently programmatic in nature. There is no thought here to suggest what all other geographers should be doing, or to suggest what geography "really" is. Identifying an ecologic stream in the development of American geographic thought simply helps clarify what may appear to be a rather chaotic mass of information, place it in a context which is becoming more familiar to those in other disciplines, and indicate how such an approach can be useful in at least one highly specific type of research. ${ }^{4}$

The paper's third section shows how ecologic concepts, particularly cultural ecologic concepts, can be applied to specific research problems in the developing countries. AIthough the eventual applications are limited only to the imagination and originality of those

\footnotetext{
${ }^{3}$ H. H. Barrows, "Geography as Human Ecology," Annals, Association of American Geographers, Vol. 13 (1923), pp. 1-14. See also M. Sorre, "The Role of Historical Explanation in Human Geography," in P. L. Wagner and M. W. Mikesell, Readings in Cultural Geography (Chicago: University of Chicago Press, $1962)$, p. 46, who says "the geographer is an ecologist by definition."

${ }^{4} \mathrm{~A}$ general statement in keeping with the present argument may be found in W. B. Morgan and R. P. Moss, "Geography and Ecology: The Concept of the Community in Its Relation to Environment," Annals, Association of American Geographers, Vol. 55 (1965), pp. 339-350. This interesting article approaches the question from a natural science point of view, but cogently argues that the ecologic approach as a scientific methodology is the important point, not the actual subject matter.
} 
using the approach, the applications already found useful will be discussed-applications in so-called adaptive research in developmental micro-economics. It should be emphasized that throughout this paper ecology is viewed as a concept, not as a theory. It is an especially useful concept in the study of developing regions because studies of a more narrow disciplinary nature have been found wanting. More specifically, approaches from anthropologic, sociologic, geographic, or economic points of view have left a great number of questions unanswered. (Such a difficulty is not unique to research on the developing regions, of course.) Of more importance, however, is the fact that these other, more specific, approaches have more often than not left a great number of questions unasked. Many of these unasked questions are among the most significant ones in problems of economic development, and the synthetic concept of ecology provides a useful approach for reaching at least preliminary answers.

\section{ECOLOGY IN THE DEVELOPMENT OF GEOGRAPHIC THOUGHT}

An exhaustive review is not undertaken here of the relevant literature in geography or other disciplines on the various aspects of ecology or the development of geographic thought. Fairly recent reviews of both subjects, with appropriate bibliographies, are available elsewhere. ${ }^{5}$ Rather, I develop a

${ }^{5}$ M. W. Mikesell, "Geographic Perspectives in Anthropology," Annals, Association of American Geographers, Vol. 57 (1967), pp. 617-34, and A. P. Vayda and R. A. Rappaport, "Ecology, Cultural and Non-Cultural," in J. A. Clifton, ed., Introduction to Cultural Anthropology: Essays in the Scope and Methods of the Science of Man (Boston: Houghton Mifflin, 1967). A collection of studies in the socalled (in this paper) human ecology is J. B. Bresler, ed., Human Ecology: Collected Readings (Reading, Mass.: Addison-Wesley, 1966). The editor of this work does not make the distinction between the types of ecologic study distinguished here. A very good bibliography, if more from the natural science side, is in D. R. Stoddart, "Organism and Ecosystem as Geographical Models," in R. J. Chorley and P. Haggett, eds., Models in Geography (London: Methuen, 1967), pp. 511-48. The author of this useful survey explicitly sets out to treat the impact of biological concepts on geography on a methodological level. A very interesting reader, primarily by anthropologists, is A. P. Vayda, ed., Environmental and Cultural line of thought which stems from a broad overview of geography as an academic discipline in the United States-an overview, to be sure, which is related to the views of others from time to time (usually for the purpose of clarifying terminology), but which in broad outline is what I see as two primary trends in past developments.

In the United States, geography formally developed out of the physical sciences, particularly geology. Much as its sister science, anthropology, has been characterized as bridging a hypothetical gap between the biological sciences and the social sciences, so geography has been seen as bridging a similar gap between the physical and the social sciences. It is not useful here to argue the phenomenological unity of nature that makes such hypothetical gaps in reality nonexistent, nor to comment on the degree to which either of these two disciplines have been successful in their self-appointed tasks of bridging the institutional and conceptual gaps which unquestionably do exist. The point is rather that this bridging function is one frequently referred to by practitioners of both fields, no matter how metaphorically, and this, in and of itself, makes the idea an integral part of the history of thought.

For more than a decade after the turn of the century William Morris Davis' view of the proper focus of geographic study was dominant. In its simplest form, this view held that the concern of geographic research should be to investigate the relationships between inorganic cause and organic effect-essentially, to study the effect of the natural environment on man. This inorganic-organic dichotomy was common to European thought of the nineteenth century. The German biologist Ernst Haeckel used it in his original definition of ecology. Davis sought a means of studying the geographic whole which had been thus conceptually divided. He was, in effect, trying to determine the place of man in nature. ${ }^{6}$

Behavior: Ecological Studies in Cultural Anthropology, American Museum Source Books in Anthropology, (Garden City, N. Y.: Natural History Press, 1969).

${ }^{6}$ An alternative view holds that Davis' suggested study of relationships was not accepted by geographers; D. R. Stoddart, "Darwin's Impact on Geography," Annals, Association of American Geographers, Vol. 56 (1966), p. 683-98. Stoddart cited Sauer who, 
This view of a one-way cause and effect relationship between environment and man is what came to be known as environmental determinism. Davis brought to the view the attitudes and training of the natural and physical sciences. His contemporary, Ellen Churchill Semple, who received part of her training in Germany, brought to environmental determinism the background and interests of the humanist. She, too, sought to determine man's place in nature, but it was man as a social and, particularly, historical animal for whom she sought a place. If Davis looked for the functional interrelations between man and environment in a general sense, Semple dealt with specific time and place interrelations. Both were concerned with what shall be identified as ecologic analysis, but Semple brought to it a somewhat more place-specific view. In spite of this emphasis on place characteristics, it was the process of man's interaction with his environment that was considered to be of prime importance; the particular spatial circumstances of the interaction were only secondary. The fact that Davis never dealt with man in any of his empirical studies is irrelevant to the impact he had on the development of this particular aspect of geographic thought.

In the next thirty years, a concern for place location, which shall be called spatial analysis, developed as a central focus of American geographic interest; there was a correlated decline in the study of both ecology and process. Here again it should be emphasized that spatial and ecologic analysis were frequently interlocked, and it should not be thought that all, or even necessarily most, studies can be readily identified as being concerned with location as opposed to process. We must here introduce another distinction, but one that shall not be presented in detail. Studies concerned with individual locations tended not to be concemed with processes. By this is meant that the element of change through time was often missing.

writing some nineteen years after Davis, disagreed with the idea of defining a science in terms of a study of relationships. Sauer did not, however, say this idea lacked influence, as Stoddart seemed to suggest.
Places, or locations, were often studied in immobile isolation with little attention given to the conditions preceding or those which were likely to follow. This static study may be distinguished from today's spatial analysis which offers a slightly more process-oriented approach. Place analysis was, however, in the view presented in this paper, the progenitor of spatial analysis, and the family likeness is still sometimes striking. For the sake of historical continuity we will call both the earlier and the recent studies spatial analysis. ${ }^{7}$ What is suggested is that trends and shifts of emphasis can be discerned. The shift towards spatial analysis was a gradual one, but the first two decades of twentieth-century geographic thought may be said to have been more oriented to ecological, process, studies.

The strongest element in the work of this era was what is now called environmental determinism, the basic idea put forth by Davis and strongly seconded by Semple. It is a mistake to consider this approach as either monolithic or naive. Davis and Semple shared the basic idea that man or society is influenced in a deterministic way by his environment; however, the actual elements which each believed entered into the interaction, and relative weights each assigned to elements in the equation, varied considerably. Nor, as has been suggested, were Davis and Semple overly simplistic in all respects. The most telling criticism of environmental determinism (as well as of any of the other deterministic doctrines, be they economic, historic, or cultural) is that the initial methodological, not to say metaphysical, position had too great an influence on the final interpretation of the data. When specific environment A was not only associated with society $\mathrm{X}$, the form of which it had presumably determined, but also with societies $\mathrm{Y}$ and $\mathrm{Z}$, which exhibited quite different forms (not to mention societies $X_{1}, Y_{1}$, and $Z_{1}$ ), the deterministic equivalent of Ptolemaic epicycles was added to the analysis to bring it into conformity with the pre-established methodological position. The strongest statements of direct determination of social effect from

\footnotetext{
${ }^{7}$ Studies of "sequent occupance," as the name suggests, were a partial exception to this characterization of earlier spatial analysis. These studies dealt with a time-series of immobile and isolated cases.
} 
environmental cause were reserved for those instances in which the factual data were skimpiest, frequently instances from very early historical periods. In other words, the main fault was that the methodological tail usually wagged the empirical dog. ${ }^{8}$

Determinism as a school of thought was primarily concerned with process and function. As the social sciences, particularly social anthropology and sociology, advanced in knowledge and technique, empirical data were accumulated that exposed more and more instances in which previously accepted cause and effect relationships were shown to be the result of incorrect analysis. In short, one of the major contributions of geographic thought for a quarter of a century was shown to have been, if not a false, then at least an overdone, lead. As a result, many rejected this broad, functional approach, and turned instead to quite different sorts of questions. These questions dealt with places, or regions -how to determine them and how to analyze them. This orientation had become fairly well established before the demise of determinism. Two very early statements by leading geographers, both basically determinists, illustrate the underlying reality of the spatial-ecologic dichotomy. N. M. Fenneman, in his address of 1918, stated that geographers should be the great synthesizers, utilizing data from diverse fields. He went on to say that "data thus assembled from diverse fields do not remain inert. They react on each other like chemicals to produce new compounds, that is, new truths." In the sort of inept metaphor too commonly found in statements on geographic methodology, Fenneman likened geographers to "the great insect that carries pollen from field to field." The end result of this aggregation of data from other fields was to be the study of the region.

\footnotetext{
${ }^{8}$ Geographic determinism and its various offshoots have received their most comprehensive treatment in H. and M. Sprout, The Ecological Perspective on Human Affairs: With Special Reference to International Politics (Princeton: Princeton University Press, 1965). See also P. A. Sorokin, Contemporary Sociological Theories: Through the First Quarter of the Twentieth Century, Chapter II: "Frederic Le Play's School," and Chapter III: "Geographical School," reprinted from the original (New York: Harper Torchbooks, 1964), pp. 63-193.
}

"Interest in places, areas, regions is the common bond." 9

Four years later, in 1922, H. H. Barrows defined geography as human ecology: ${ }^{10}$

Geographers in increasing numbers define their subjects as dealing solely with the mutual relations between man and his natural environment. By 'natural environment' they of course mean the combined physical and biological environments. . . Thus defined, geography is the science of human ecology.

Barrows further insisted that field work was essential, thereby correcting Fenneman's implied neglect of it in favor of library research.

Thus by the first quarter of the century, Fenneman and Barrows, two leading geographers who were both essentially determinists, were advocating two distinct programmatic positions: one spatial, the other ecologic. The intertwining of the two currents is evident, but the difference in emphasis is equally obvious and eventually much more formative. The view of Fenneman was to prevail in the years immediately following. ${ }^{11}$

When deterministic study was found to be a wrongly-defined process, geography fell into some disrepute with scholars in other disciplines, and a reaction occurred within geography, one which emphasized a microregional approach. This approach was not just non-theoretical or a-theoretical, but almost anti-theoretical. It was developed primarily at Chicago, although it eventually spread elsewhere, and shall be referred to here as Midwestern regionalism. We may take as the archetype of this development the work of Robert S. Platt, who may have been the originator, and was certainly the most dedicated user of, the term micro-geography. This approach called for the detailed and

${ }^{9}$ N. M. Fenneman, "The Circumference of Geography," Annals, Association of American Geographers, Vol. 9 (1919), pp. 3-12.

10 Barrows, op. cit., footnote 3.

${ }^{11}$ In a recent article, Koelsch has cogently argued that Barrows was not a strict environmental determinist at any time. This is certainly true and he is here grouped as a determinist only in the grossest sense. Koelsch, following Lewthwaite, views Barrows as an "environmentalist," a term closely equivalent to "ecologist" in this paper. W. A. Koelsch, "The Historical Geography of Harlan H. Barrows," Annals, Association of American Geographers, Vol. 59 (1969) pp. 632-51. 
relatively exhaustive description of small areas: $\mathbf{1 2}^{12}$

A bit of regional geography dealing with minute area. In such an area intensive study has been possible, and in the presentation the many facts need not be reduced to sweeping generalization.

A great number of such studies were carried out, an impressively large proportion by the indefatigable Platt himself. In a very real sense this was a reversion to a Baconian view of the data-collection aspects of science without attempting to formulate hypothesis or deductive theory. ${ }^{13}$

The investigation represents a type of geographic experiment, and might later, with other detailed studies, form the basis for significant generalizations. The study . . . is a primary case, an elementary unit in the science of geography.

Studies undertaken from this point of view were non-theoretic, since they could not serve the basic purpose of data accumulation in science. They were non-cumulative-one was not built upon the premises or hypotheses established by previous ones. The discipline was left with a plethora of non-cumulative descriptive studies of small places.

Micro-geography of this scale and for this purpose was basically an American product. Another areal or spatial approach was a carryover from Germany. This was the study of macro-regions, a geography intent upon sorting out all the phenomena of the world into world regions. Such work had been, or was being, done for many physical phenomena such as climate, physiography, and vegetation, and attempts had been made in the late nineteenth century to apply the technique to social phenomena as well. This macro-regional work was continued and refined in the broad framework of Midwestern regionalism. While it was also basically a-theoretical and noncumulative, at least within the field of geography, it has probably been of greater value to scholars in other disciplines than microgeographic studies. The delineation of world

${ }^{12}$ R. S. Platt, "A Detail of Regional Geography: Ellison Bay Community as an Industrial Organism," Annals, Association of American Geographers, Vol. 18 (1928), p. 81 .

${ }^{13}$ F. S. C. Northrop, The Logic of the Sciences and the Humanities (Cleveland: World Publishing Company, 1959), Chapter 3, "The Natural History Stage of Inquiry." Quotation from Platt, op. cit., footnote 12 . regions has often served others as the geographic equivalent of historical periods. Like historic periods, world region delineation will never satisfy the specialist, but it may often serve the non-specialist well. ${ }^{14}$

There was, during this same period, a second major development in America-the Berkeley school of cultural geography. Centered around the person of Carl Sauer, the cultural geographers maintained close ties with anthropologists, sharing with them a desire to identify culture areas and to seek historical origins and paths of diffusion of the areal culture traits. Much of the work was of a place variety-the search for culture areas stemmed in the first instance from the needs of museums to classify their exhibits in an areally meaningful way.

There was, however, a strong ecologic cast to other work done by this school. The study of man using, and living on, the earth, the earth-as-the-home-of-man approach, became quite strong. ${ }^{15}$ Much attention was given to the obverse of the environmentalist coin, the effects of man on the environment, which eventually gave rise to a form of cultural determinism; but that was another, and later, development. Such work was not done under the name of ecology, perhaps because Sauer had taken strong exception to Barrows' assumed slighting of the role of physical geography in his paper on ecology. Earlier, Sauer took as his model the study of morphology and translated this into a continuation of the German school of landscape study. Here, too, the distinction between place study and ecologic study was extremely vague, for the study of in-place process and function led to

\footnotetext{
${ }^{14}$ Micro-regions, as objects of geographic study, received very early criticism from other regional geographers. P. E. James, "The Terminology of Regional Description," Annals, Association of American Geographers, Vol. 24 (1934), pp. 78-92, questioned the scale of study but not its methodological justification. James felt that small regions could not provide generalizations suitable to large regions, but did not comment upon the Iack of systemic analysis, which is viewed in this paper as the most serious weakness of the regional approach.

${ }^{15}$ W. D. Pattison identified this as one "tradition" of geographic thought which has had great impact on geographic education in the United States. His discussion may be found in "The Four Traditions of Geography," The Journal of Geography, Vol. 63 (1964), pp. 211-16.
} 
the recognition of properly delimited landscape. ${ }^{16}$

A further note of clarification is now needed regarding the distinction between spatial and ecologic analysis as distinguished here. If the two blend and merge so often and are so vague, what is the point in insisting upon their distinction? Even granted some distinction, what is the relationship between them? A partial answer to the relationship question provides an answer to the one of distinction. It is clear that in both the Midwestern and the Berkeley school the so-called spatial and ecologic approaches are partially questions of scale. The study of functional interaction of phenomena, or ecologic analysis, in one instance, may become the study of place in relation to other places at the next higher level of generality. The distinction, however, is one of focus: one must determine whether a study was explicitly or implicitly conceived as being concerned with functional interactions of phenomena (albeit in a specific place), or whether it was conceived as a study of those phenomena as they combine to form a distinct areal entity, connected and similar or not to other such entities. Whereas on the one hand these analyses may be viewed as simply two different approaches to the same phenomena, on the other hand they differ enough so as to distinguish two streams of thought-two sets of mental attitudes, if you will. The crucial point is that each approach lends itself to the use of different theory, methodology, research design, and techniques of investigation-in short, two distinct styles of scientific approach. Intimately tied to this justification, and eventually much more important, is the fact that the different approaches arise out of, and lead to, different questions. Later it will be shown that the ecologic approach is associated with theories of other behavioral sciences which deal with problems of economic development in the underdeveloped world. ${ }^{17}$

\footnotetext{
${ }^{16}$ C. O. Sauer, "The Morphology of Landscape," University of California Publications in Geography, Vol. 2 (1925).

${ }^{17}$ An attempt to infuse a behavioral component into spatial analysis was made in A. Pred, Behavior and Location: Foundation for a Geographic and Dynamic Location Theory, Part I. Lund Studies in Geography, Series B, Human Geography, No. 27 (Sweden: The Royal University of Lund, 1967).
}

Specifically, these sciences are anthropology, sociology, and micro-economics.

While ecologic and spatial analysis may be distinguished by the sorts of questions asked and the styles of scientific approach used in determining the answer, the two types of analysis are, after all, dealing with the same set of phenomena and must therefore have elements in common as well.

Spatial analysis is concerned with factors affecting the location of specific activities. These factors can be assigned weights in any given instance and can eventually be ranked by importance for that activity at that time. In agricultural location some of these factors will be features of the natural environment: soil, temperature, slope, and hydrology. Others will be social-more specifically, economic-in nature. The distance from market or dwelling and transportation routes will be of importance; the importance will vary with the nature of the activity and the level of social and technological organization involved. For shifting cultivators, for example, the distance from dwelling, even a temporary dwelling, is much more heavily weighted than the distance from market, which often has almost no weight at all, and the distance from water may be of more importance than all the rest combined.

Ecologic analysis is concerned with the interaction of the factors which define the activity itself, rather than with how the factors affect the location of the activity. Ecologic analysis concerns itself with the emergent system formed by the factors' interaction and with analyzing how the system functions. Locational analysis, in a sense, begins where ecologic analysis leaves off-it takes the system investigated in ecologic analysis as given and goes on to relate it to location, albeit without specifically stating this aim.

It is possible to have ecologic analysis in which the location is given: the investigation focuses only on the emergent interacting system. The area of overlap between ecologic and spatial analysis comes when the spatial analyst concerns himself with the components of the ecologic system as such to determine the relative weights to be assigned, and when the ecologic analyst considers locational factors as such to determine how they effect the 
functioning of the ecologic system. There is thus a continuum with ecologic analysis at one end (taking location factors as given), spatial analysis at the other (taking the ecologic system as given), and an overlap in the middle where elements from one end of the continuum are considered from the point of view of the other. ${ }^{18}$

What is in fact being sought is a series of emergent systems (to borrow a phrase from Parsons' sociology). Let us not confuse this sort of system with what is currently called General Systems Analysis-the term "system" is used here almost in its lay sense of a series of ordered events operating as a whole. ${ }^{19}$ More specifically, ecologic analysis seeks, or the aim of ecology is, a series of studies which will help identify the underlying unity of what might appear to be dissimilar cases. In order to do this it is often necessary to separate out analytically those specific interactions which prove to be most important in the real world and to recombine them, analytically, into a new, emergent system. Put another way this means that we take certain sets of interactions from the empirical system and then look for the same type of sets in different

\footnotetext{
${ }^{18}$ It seems necessary here to clarify a point that might be raised against this view. Superficial reading could lead to the idea that what is being advocated is a series of studies of unique, in-place, situations. Much argument has recently centered around the unique vs. general, or ideographic vs. nomothetic, dichotomy. We need not repeat the often mistaken views of both sides (mistaken in that advocates of one position or the other frequently either don't read, mis-read, or misinterpret the writings of their predecessors) but rather may simply point out that the untenability of such a strict dichotomy has been shown by E. Nagel, The Structure of Science: Problems in the Logic of Scientific Explanation, (New York: Harcourt, Brace \& World, 1961), pp. 547-51.

${ }^{19}$ An attempt at a slightly more formal system construct will be found in W. Isard, "Some Notes on the Linkage of the Ecological and Economic System," Papers, Regional Science Association, Vol. 22 (1969), pp. 85-96. After making the somewhat bizarre observation that the combination of the words ecologic and economic is "unusual" (they have in fact a common root and retain considerable common meaning), he stated that "the combination is a true combination, in the sense of a synthesis of analysis of two systems within the world of actuality." Isard then proceeded to attempt a synthesis of two highly analytical systems which intellectually separate what is in fact a single system within the world of actuality.
}

empirical systems. This allows us to make systemic comparisons and, hopefully, to understand the actual underlying unity of superficially different reality.

From such comparative study we may conclude, for example, that the subsistence activities of the Eskimo, the Bushman, and the Negrito aborigines of Malaysia are systemically identical, in spite of the extreme differences in the material attributes of their societies and cultures, and presumably more important to geographers, in spite of the extreme differences of their habitats.

Interdisciplinary exchange, whether in the form of ideas or people, has been an important part of American geography from its inception. One of the unhappiest results of the retreat from the analysis of environmental influences by the Midwestern geographers was an evident withdrawal from exchange with research in other disciplines. This was most evident in economic geography, but also may be seen in other parts of the field. There was seldom evidence, explicit or implicit, of an awareness of overlapping research being done elsewhere. Such academic chauvinism is not limited to geography, but not all disciplines have been so dependent upon other disciplines (nor so well rewarded for being so). A part of this ill-founded attempt at independence may be attributed to a search for an identity. In a continuation of previous approaches, this took the form of attempts to define an object of study, the region, that was uniquely geographic. The false lead of environmental determinism caused people to reject a study focused upon relationships. The unhappy result was a partial rejection of the whole approach to functional analysis. Instead, the region was to be the object to which geographers were to direct their attention; the identification and comparison of regions was what geography was about. Fenneman had triumphed over Barrows. ${ }^{20}$

\footnotetext{
${ }^{20}$ The origins of the regional approach in Germany during the nineteenth century have been discussed in J. Leighly, "Methodologic Controversy in Nineteenth Century German Geography," Annals, Association of American Geographers, Vol. 28 (1938), pp. 238-58. The development of the regional theme in American geography between the two World Wars has been discussed in some detail in Leighly's translation of G. Pfeifer, Regional Geography in the United States Since the War: A Review of Trends
} 
Looking back with the advantage of hindsight, it is evident that the regional geography of that period did not prove very productive. The work of geographers attempting to identify regions of various sorts had gone virtually unnoticed, and presumably unmissed, by most of those in other disciplines. Partially from a lack of rigor, partially from a lack of awareness of what was being done in other fields, and partially, perhaps, from the difficulty of identifying and analyzing such complex concepts with the methodology and techniques then available, geographers became further and further removed from the rest of the academic community.

World War II saw many geographers called into government service as experts on specific world regions. The regionalism espoused for the previous two decades or so was called upon to produce specific knowledge which could be put to practical use, but in many instances the regional specialists, as such, could be of little use. They had little foreign language training, many had done no field work and thus lacked first-hand knowledge of other parts of the world, and almost all were ignorant of, if not antagonistic to, the work done in other behavioral disciplines, such as anthropology or sociology. Their approach was that advocated by Fenneman. They compiled facts collected by others and synthesized those facts into regional studies. At least for the initial purposes they were called upon to serve, geographers lacked any theoretical or methodological base and had an inadequate knowledge of those parts of the world with which they were supposed to be most familiar. ${ }^{21}$

Following World War II at least two major trends developed in the discipline. One was the so-called Quantitative Revolution, a revolution which came to geography almost a decade after it did to other academic fields. The other was the development of area

in Theory and Method, (New York: American Geographical Society, 1938).

21. This subject has been treated in some detail in E. A. Ackerman, "Geographic Training, Wartime Research and Immediate Professional Objectives," Annals, Association of American Geographers, Vol. 35 (1945), pp. 121-43. On page 127 he says "our deficiencies can be explained by the pre-war emphasis on the regional method in training and research." studies, as such. These latter should not be confused with the earlier regionalism, for now the approach to the study of other cultures and societies was more firmly based on the prerequisite trilogy for foreign area research-language training, interdisciplinary training and field work. In neither the new quantitative nor the new area studies do we find the development of an even more basic scientific requirement-new theories and methodologies. Those working in quantitative studies (this phrase has been used, as it is here, to cover a remarkably wide range of very dissimilar work) and those in area studies had in common the tendency to ask the same sorts of questions asked by their much-maligned predecessors. On the quantitative side were frequently found complex and detailed analyses of trivial problemsthe answers to many of which had been known for decades-while on the area study side were often found profound and learned commentaries on esoterica reminiscent of the nineteenth century natural historians.

The spatial and the ecologic analytic approaches are not so distant from one another as they might at first appear to be. Geographers who use quantitative methods (what they are fond of calling non-verbal notation) have introduced a rigor of technique and a formulation of thought sadly lacking in many studies of an earlier period. Consequently, they have challenged their colleagues to tighten up their analytic approaches. Conversely, geographers working in area studies have sometimes been able to indicate the value of being widely read and literate in presentation, particularly emphasizing the desirability of interdisciplinary training and a sense of time-scale. If little interbreeding has taken place in recent years, the families have at least come to be on speaking terms.

Studies of an ecologic nature, however, have not been common in the postwar period. Those few studies made from an ecologic point of view have been mostly in biogeography (i.e., relatively "pure" ecology) or have dealt with prehistoric or primitive human populations. Many have been made by students of Sauer, or by students of his students. Few studies seem to have been made by younger members of the profession and fewer still are directed to either inter- 
disciplinary or practical research. This may be attributed to various factors: the rise of spatial analysis, which uses the sophisticated equipment of some of the more technologically advanced sciences, has attracted some of the better minds; the attempts to study man as a functioning part of nature is associated with environmental determinism, and is considered to be either incorrect or old-fashioned; and the cultural geographers, from whom one could expect work of an ecologic nature, tend to be identified with the anthropology of the 1930's and are either attached to the culturearea approach, or are limited in their work to preliterate peoples, or both. ${ }^{22}$

${ }^{22}$ Recently there has been a welcome resurgence of work of an ecological nature. Appropriately enough, much of it has been done by geographers currently or formerly associated with the University of Chicago, for example, I. Burton, R. W. Kates, and G. F. White, "Human Ecology of Extreme Geophysical Events," Natural Hazard Research Working Paper No. 1 (Toronto: Department of Geography, University of Toronto, 1968). It is unfortunate that the authors of this useful paper, which deals with what is here called "cultural ecology", evidently felt that the term human ecology needed no further definition than that given by Barrows in 1923. A similar assumption is implicit in I. Burton, R. Kates, and R. Snead, The Human Ecology of Coastal Flood Hazard in Megalopolis, Research Paper No. 115 (Chicago: Department of Geography, University of Chicago, 1969). In this latter work the only attempts at definition seem to be the very general statements that "flood-plain occupance represents an interaction between the requirements of a human system involving economic, social, and spatial requirements and relationships; and a hydrological system characterized by risks of extreme fluctuations," p. 5, and "the shores of Megalopolis provide the meeting ground for two major systems-man and nature," p. 177. The natural hazards of assuming a common basis of understanding of ecological concepts and terms has been amply demonstrated in $\mathrm{H}$. and M. Sprout, op. cit., footnote 8 , and again by the same authors in An Ecological Paradigm for the Study of International Relations, (Princeton: Center of International Studies, Princeton University, 1968). Other work on "factorial ecology" would better be titled "factorial chorology," as it follows a sociological use of the term which is described in the following section; B. J. L. Berry and P. H. Rees, "The Factorial Ecology of Calcutta," The American Journal of Sociology, Vol. 74 (1969), pp. 445-91, and R. A. Murdie, The Factorial Ecology of Toronto, 19511961: An Essay on the Social Geography of the City, Research Paper No. 116 (Chicago: Department of Geography, University of Chicago, 1969). A recent article of some interest is S. Y. Hsu, "The Cultural Ecology of the Locust Cult in Traditional China,"

\section{ECOLOGY AS A MANY-FACETED CONCEPT}

Before proceeding further it is obviously necessary to be more explicit about the various usages of the term ecology. Both the word and the concept have been subjected to a variety of uses and misuses. Originally, the word was used in the late nineteenth century by the German scientist Haeckel who, in at least one instance, meant by ecology the "external physiology" of organisms-the relations of organisms to their (inorganic) environment (relation physiologie). ${ }^{23}$ This natural science usage was developed in the United States in botany for the most part and, at the University of Chicago, botanical ecology was used as a model for urban ecology. However, urban ecology was ecology only by analogy, for it borrowed only the spatial and temporal terms of botanical ecology (succession, regression, competition, climax community) and not the study of interaction between the environment and the environed, except in the sense that environment partially consists of other, similar, environed units. Haeckel had suggested that ecology, as he set it forth, should be complemented by the study of chorology (a familiar geographic concept) which would be the study of the spatial, both vertical and horizontal, distribution of organisms. Had chorology become a prominent term, the urban sociologists would have recognized that their work was, in fact, urban chorology rather than urban ecology. However, the point is that the earliest social science use of the term ecology was by analogy only. ${ }^{24}$

Annals, Association of American Geographers, Vol. 59 (1969), pp. 731-52.

${ }^{23}$ The historical development of the general idea, if not the name, of ecology shows an interesting fluctuation between social and natural science. Haeckel was influenced by Darwin. Darwin, who did not himself use the term ecology but who ex. plicitly concerned himself with the subject matter and viewpoint, had been influenced earlier by the writing of Malthus, whose population/food supply equation is a central tenet of the ecologic concept. For Darwin's role, see D. R. Stoddart, "Darwin's Impact on Geography," op. cit, footnote 6 .

${ }^{24}$ That ecology by analogy remains with us has been pointed out by O. D. Duncan, "From Social System to Ecosystem," Sociological Inquiry, Vol. 31 (1961), who warns against such use on the part of the economist Kenneth Boulding. Duncan anticipated many of the remarks contained in the present 
In the early 1920 's, also in Chicago, Barrows was advocating geography as human ecology. The theme "man in nature" was hardly new to the discipline, although it was perhaps more central to European than to United States thinking. George Perkins Marsh had elaborated on it in the late nineteenth century, but his work was ignored in the United States until the 1930 's. It was an appropriate theme for a field of inquiry which has its intellectual origin in a desire to place human society in a broad frame of reference.

Like geographers, anthropologists wished to investigate man and his works within a framework of natural and man-specific phenomena. Anthropology has a history of interest in ecologic studies at least as long as geography's; at the present time, in both fields, studies are being made with explicit as well as implicit ecologic points of view. However, anthropologists approached ecology biologically, while geographers (to oversimplify) did so geologically, which may help account for some of the distinction between the ecologic studies done today in each field.

These different approaches have been characterized elsewhere as studies in human ecology and studies in cultural ecology. In human ecology, human populations are viewed in much the same way as populations of any other sort of organism. As such, human groups may be dealt with in terms of reproduction rate, energy exchanges, sex ratios, biomass consumption, or any of a variety of techniques and measures appropriate to biological ecology studies. The populations are not, however, distinguished in terms of channels of decision-making, patterns of leadership, economic distribution and consumption groups. These groups are more frequently found in studies of cultural ecology, particularly studies which deal with man as a culture-bearing animal, rather than solely as a social animal. ${ }^{25}$

paper when he suggested that the ecologic approach provides a systemic analysis of "systems that cut across levels" (italics in the original), p. 141. The levels referred to are the levels of scientific organization of data summarized by A. L. Kroeber as the inorganic, organic, psychic, and sociocultural.

${ }^{25} \mathrm{An}$ elaboration of this point, as well as an empirical study based on this methodological position, is found in J. D. Clarkson, The Cultural Ecology of
It must not be thought that we have here a clear-cut distinction. Once again we find two types of work intertwined, with the emphasis now on one, now on the other, and often some confusion of the two within the same study. Although it is bootless and churlish, as well as intellectually unsound, to suggest one form of study over the other as being somehow more correct or more scientific, it is not unscholarly to argue that if a study deals with a population at one point as simply another animal population, but at another as a socially and culturally ordered grouping, confused reasoning may result. It is simple to slip from a discussion of a population qua animal population to a discussion of the same population qua society without explicitly recognizing the abstract nature of the latter unit; the attendant danger of assigning a biological cause from the first analysis to a social effect from the second is obvious. $^{26}$

Human ecology will naturally draw upon and add to theory and methodology from the natural sciences, presumably biology, while cultural ecology will find roots and send tendrils towards sciences of society-economics and sociology, perhaps.

In more recent times, in two other fields of enquiry, studies have developed which are explicitly called ecologic. The first is an amalgam of disciplines drawn together, often under governmental auspices, for pragmatic purposes; the so-called environmental sciences have been founded to deal with problems of pollution of waterways, atmosphere, and city streets. It seems likely that environmental

a Chinese Village: Cameron Highlands, Malaysia, Research Paper No. 114, (Chicago: Department of Geography, University of Chicago, 1968).

${ }^{26} \mathrm{~A}$ recent explicit statement of human ecology in which the author is careful not to make such an error has been made by the anthropologist $R$. A. Rappaport. "A population may be defined as an aggregate of organisms that have in common certain distinctive means for maintaining a set of material relations with the other components of the ecosystem in which they are included. The cultures of human populations, like the behavior which is characteristic of populations of other species, can be regarded, in some aspects, at least, as part of the "distinctive means' employed by the populations in their struggles for survival." R. A. Rappaport, Pigs for the Ancestors: Ritual in the Ecology of a New Guinea People (New Haven, Conn.: Yale University Press, 1968), p. 6. 
studies will be made by scholars and engineers from various natural and physical sciences. Implementation of sound scientific findings may be hampered by their insufficient awareness of political and social forms as well as the "natural" ones. The studies will probably be of a human ecologic nature in that they will deal with man and with his activities as they serve to deteriorate his physical environment, but the pragmatic purposes they were designed to serve will be hampered by the lack of parallel, or interrelated studies, of a cultural ecologic nature.

Political science, or more precisely, public administration, is the other field of inquiry in which the term ecology has made a recent appearance. The writer wishes to suggest that others in his discipline become aware of external, non-political phenomena-that they recognize that political action is embedded in non-political institutions and groupings, as well as in the non-human environment; without considering these factors the significance of political action can be missed. ${ }^{27}$

Of immediate concern are the uses of ecology in geography and anthropology (Fig. 1). Curiously enough, the anthropologists' position seems to be moving more toward natural sciences and the geographers' more toward the social sciences. ${ }^{28}$ This means only that those investigators in each discipline who

${ }^{27}$ F. W. Riggs, The Ecology of Development, (prepared for presentation to the Comparative Administration Group, Bloomington, Indiana, 1964). After reiterating what is known in anthropology and geography about the relation of technological and social complexity to habitat-modifying capability, Riggs added a much-needed behavioral element by relating his ecologic résumé to the goal-oriented nature of government systems.

${ }^{28}$ Curiously, because one of the earliest, most comprehensive, and influential modern methodological statements about ecology in anthropologic research is J. Steward, Theory of Culture Change, (Urbana, Ill.: University of Illinois Press, 1955). Again, boundaries are indistinct, but Steward's work is more about cultural ecology, as described in this paper. A further instance of cultural ecology is C. Geertz, Agricultural Involution: The Process of Ecological Change in Indonesia (Berkeley: University of California Press, 1966). These works are concerned with social organization and structure of human populations in relation to their milieu. Early geographic statements tended to ignore social organization and dealt with human populations as another animal population. It is more difficult to find a specific methodological statement of this approach

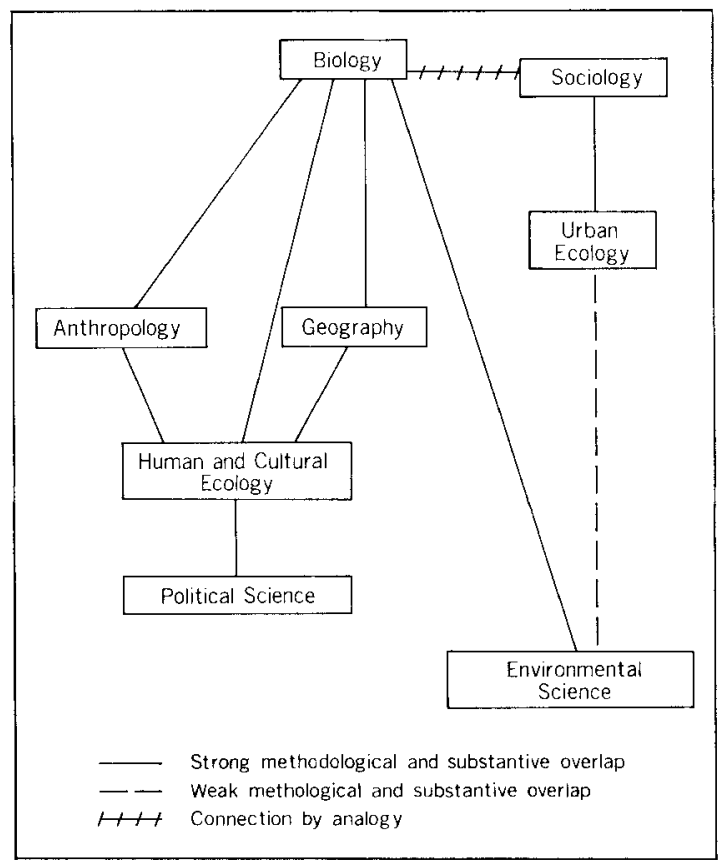

FIG. 1. The family tree of the ecology concept.

explicitly see themselves as working on ecologic problems may be moving in different methodological directions which, considering the essential unity of the phenomena under study, should eventually lead to the same goal. The approach of human ecology is a bit more popular in anthropology than it is in geography. It may be that this emphasis is more appropriate to the traditional subject matter of social anthropology-small, relatively isolated groups of primitive people. Cultural ecology, on the other hand, seems more suited to studying groups of somewhat greater complexity and size. It is feasible, if difficult, actually to measure the energy intake of a band of primitive cultivators, but it is not feasible to do so for a peasant village, let alone an urban population.

Of the types and trends of ecologic analysis in various disciplines today, biologic ecology

because of the reluctance of earlier writers in geography to make such explicit remarks. See however, C. O. Sauer, "The Agency of Man on Earth," in W. L. Thomas, Jr., ed., Man's Role in Changing the Face of the Earth (Chicago: University of Chicago Press, 1956), still the best single compendium of ecologic studies of both a human and cultural type. 


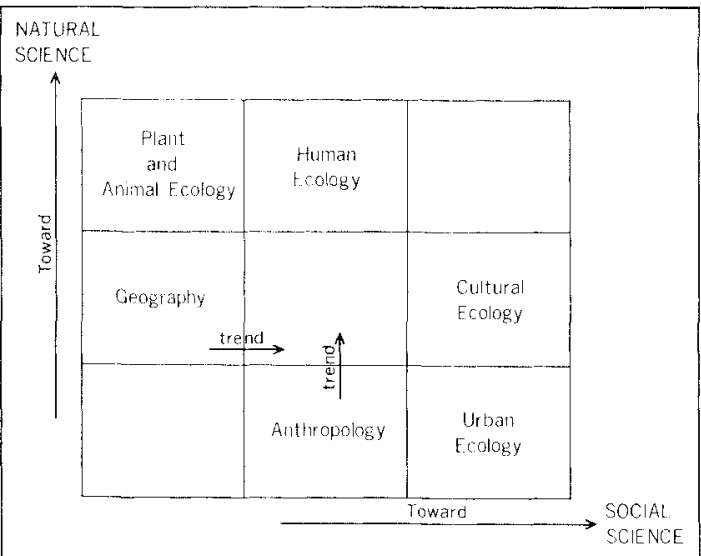

FIG. 2. Types and trends of ecological analysis.

represents the purely natural science approach, and urban ecology, by way of contrast, represents pure social science (Fig. 2). Geography, which began mid-way on the natural science scale, seems to be moving more toward the social sciences, i.e., toward cultural ecology, whereas anthropology, from a beginning in the middle of the social science scale, seems to be moving in the direction of the natural sciences, i.e., toward human ecology.

\section{ECOLOGY AND ADAPTIVE RESEARCH}

We come now to the possible uses of the ecologic concept, especially with the use of cultural ecology, in pragmatic planning and action. In recent years, there has been a call for "adaptive research" by developmental economists and agronomists. This refers to the need for research in situ, research less designed and oriented toward economic theory and more problem oriented.

Such adaptive research is, by its very definition, ecologic in nature. There is no point in making disciplinary distinctions-sociologists, anthropologists, economists, geographers, everyone interested in and concerned with the problems under investigation is needed. In fact, the failure of strictly disciplinaryoriented work to produce satisfactory results has made the need for a new approach obvious. ${ }^{29}$

${ }^{29}$ A similar point has been argued very effectively by Byrnes, op. cit., footnote 2. See also G. Myrdal, Asian Drama: An Inquiry into the Poverty of $\mathrm{Na}$ tions (New York: Pantheon Books, 1968). In his
Perhaps the point can be illustrated by reference to specific examples. One of the problems which faces those who attempt to improve agricultural practices in many parts of the world is getting local cultivators to accept innovation. Many well-laid plans have failed to reach fruition because the people for whom the plans were designed simply would not accept them. A clearer understanding of the potential barriers to the innovation's acceptance can be gained by analyzing the problem from what we have previously defined as a cultural ecologic point of view. In this case, we shall assume the planner represents a government agency.

First, one can distinguish at least three, perhaps four systems of events (ecologic systems) which compose reality. "Ecologic system" means not only the crop ecology, or botanic or zoologic ecology, but the salient aspects of the social and economic structure, and the thought patterns involved.

The first aspect of reality is the system viewed by the cultivator himself. We may call this the pragmatic aspeot. From his personal knowledge, the man who works the land has ideas about that land, has usually highly detailed knowledge about it, knows what it can and cannot do within the limits of the technology with which he is familiar, is well aware of minor or major local variations, knows the crop history of the area, and has a wealth of similar detailed knowledge.

methodological "Prologue" Myrdal argues for an understanding of the social and institutional structure of non-Western societies, and thus an approach free from the artificial boundaries of the Western academic disciplines, i.e., adaptive research. Myrdal stated, pp. 26-27:

"Not only is the social and institutional structure different from the one that has evolved in Western countries, but, more important, the problem of development in South Asia is one calling for induced changes in that social and institutional structure, as it hinders economic development and as it does not change spontaneously, or to any very large extent, in response to policies restricted to the 'economic' sphere.

"The essential first step toward an understanding of the problems of the South Asian countries is to try to discover how they actually function and what mechanisms regulate their performance.

". . what is needed is a different framework of theories and concepts that is more realistic for those societies." 
$\mathrm{He}$ is also well aware of the realities of $\mathrm{fi}-$ nancing such a small enterprise, and of what he and his family need in the way of foodstuffs, clothing, ceremonial funds, tools, and seeds. He has an intimate knowledge of where these are likely to be available and from whom. He knows, from daily experience, what debts and obligations he must incur to obtain his needs and wants, and he exists within a well-organized and recognized network of social ties which will supply most of his needs and wants at a predictable cost, monetary or otherwise. Furthermore, and more importantly for this analysis, what he sees is an entire and more or less intelligible whole, with known characteristics and predictable reaction patterns. This set of natural and social phenomena is seen, and indeed functions, as a single system from the cultivator's point of view. There is little distinction between economic and non-economic, or between that aspect of his life which concems his farm, that which concerns his family, and that which concerns his fate.

The second aspect of reality is the generalized attitudes and actions of personnel working for government agencies which are attempting to introduce change. The government's view is based on an idealized reality which the government is hoping to bring into being. The attempt is to change the existing system into something new, and that new something is, in almost all instances, a rational, or at least rationalistic, scientific, value-determined objective. Government plans, again almost by definition, are prescriptive, and we may characterize this as the prescriptive aspect. As such, the view of the cultivator is often taken as a personal or national insult, not as a sensible response to pragmatic problems over a long period of time. Government, through its agents, wants to change those parts of the cultivator's world which it believes are barriers to progress. Most frequently, the proposal for change initially involves items of material technology such as tools, seeds, fertilizers, and irrigation works. Often, too, the proposal involves attempts by government agents to apply abstract and generalized plans to concrete and specific situations, and little attention is paid to the possible existence of minor, but crucial, differences in the two. Thus, agents may attempt to get a cultivator to plant a certain crop in area $X$ because the land-capabilities map shows that area to be suitable-e.g., to have the proper soils, or rain-fall, or location. The cultivator may be reluctant to do so because he knows that in that particular spot the ground is water-logged, or the soil is unusually acid, or the area is subject to inundations of sea-water. These objections will frequently be put in folk terms-the soil is sour, or the area has a bad spirit-which will cause the government personnel to discount the cultivator's argument. Furthermore, the agent may attempt to introduce just one element into the complex web of interaction in which the farmer exists, and the attempted introduction might be potentially disruptive to many other aspects of the system. For example, if the farmer gets his seeds, tools, and fertilizer from a merchant who also lends him money for ceremonial needs (marriages, deaths, and births), he may well be cutting himself off from potential sources of ceremonial funds if he accepts alternate sources of farming technology. In many instances, the distinction of different elements which seem so obvious to the change agent are simply not distinctions made by the cultivator himself.

Western economists have frequently "trained out" of Asian students studying abroad what would, upon their return to their own countries, be much-needed common sense, partially because economists see a different reality from the rest of the functioning world. For many economists and geographers the "real" world is one of soil, crops, comparative advantage, supply and demand, and transportation infrastructure. They and the theories they espouse exist professionally in an ideal world. The world of grubby politics, nationalism, prejudice, primordial loyalties, and all the rest of the flesh and blood reality in which economic activity is embedded is not recognized as being on the same order of reality.

A third aspect of reality may be called, with due recognition of the various philosophical difficulties involved, the objective reality of a trained and relatively impartial observer. This is the reality of the worker in ecologyat least as ideally set forth here. This should be, so far as possible, the unbiased world of appraised fact-fact dealing with the appropriate set of interacting elements in the eco- 
logical system and, perhaps more importantly, facts dealing with the distinction between pragmatic, prescriptive, and objective realities. The ability to make this latter distinction justifies the attempt to use a cultural ecologic approach.

A fourth aspect of reality, the cultivator's ideal reality, may exist, or at least be operable in this context. This is the interacting system that the cultivator thinks should be operating. It may be that the cultivator, like almost anybody else, recognizes consciously or unconsciously ideal arrangements and actual (existential) arrangements. Some of the ramifications of the ideal reality are discussed below.

The question now is, what, if any, practical difference does it make if we choose to look at the problems of introducing innovation in terms of sets of reality? Do we really enhance our understanding by so complicating our analysis? Let us see precisely how this mode of thought may help solve some of the problems indicated.

We have already indicated the well-known fact that attempts to introduce innovations to peasants or farmers frequently fail for seemingly inexplicable reasons. We hope now to explain some of those possible reasons. If a government agent works solely within the framework of his own prescriptive reality, he may stumble over two obstacles. In the first place, he may be suggesting a new idea or technique which goes against everything the farmer knows about the piece of land he is working. The agent may, in other and more direct words, be trying to teach his grandmother to suck eggs. This probably happens much more frequently than one might suspect, particularly when the agent is young, of foreign training, and of urban origin. The effect of trying to tell a farmer to do something that any local ten year old knows will not work is seldom limited to the immediate instance. The next time an agent attempts to convince the local cultivators to try something new they will recall previously incongruent attempts and be more prone to reject the new one no matter what its intrinsic merits might be. ${ }^{30}$ The second obstacle is

\footnotetext{
${ }^{30}$ This may be called the "cumulative and spiral effect." It works in either innovation acceptance or rejection and, simply stated, refers to the impact of
}

more directly concerned with the concept of cultural ecology. If the change potentially replaces an element of the highly integrated set of economic, social, and cultural pieces of the cultivator's life, but takes no account of this integration and potential disintegration, then the farmer's awareness that a whole segment of his life will likely be changed will be a hidden obstacle in acceptance. In some instances, this may not make much difference in the final decision to accept or reject change. Those instances would be when the change is of such overwhelming and obvious benefit as to make other considerations seem trivial; e.g., it will immediately, and for some forseeable future period, triple the cultivator's real income. Such potential changes, however, are all too rare. More likely the potential change would, perhaps, increase real income (if that is the measure) by ten percent, and there would seldom be any guarantee of even that increase for any length of time. In such instances, which are the most common by far, the individuals making the decision to change are naturally conservative; i.e., in the face of what may well be ill-conceived advice, they prefer to conserve what little they have.

The potential importance of the fourth reality, the ideal reality, now becomes apparent. Even if one were to successfully train government agents to be aware of, and appreciate the practical complexity of, the concept of cultural ecology, attempts to introduce appropriate and well-advised change might still fail, because yet another reality was unrecognized, and the newly-sensitized change agent would still stumble over the invisible barrier of an ideal system. Let us assume he has carefully analyzed both the objective reality, and the government's prescriptive reality and plans, and has amalgamated all these into an objective, working synthesis with the cultivator's pragmatic world. He still may find that the proposed change will not be accepted because it goes against, not the pragmatic reality of the culti-

previous experience of a similar nature upon each new instance. Groups which have previously accepted (or rejected) innovation are more prone to accept (or reject) further innovation, and this process tends to continue in the same direction at an everincreasing rate. 


\section{A. Investigator's Objective Reality}

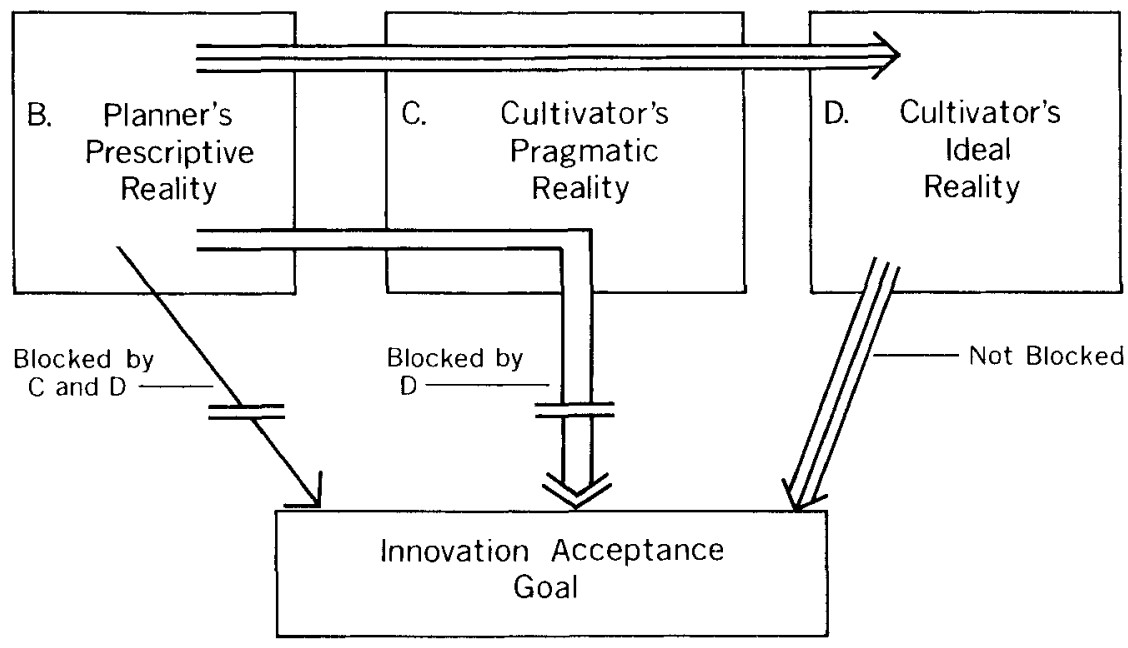

FIG. 3. Schematic diagram of the four orders of reality.

vator, but the cultivator's view of what reality should be like.

An instance has to do with the Islamic injunction against taking monetary interest on loans. In the real world interest accrues to money-lenders and others whatever their religious preferences may be. If the government wishes to regularize and stabilize interest rates, however, and says as much to Moslem moneylenders, they will point out that moneylenders could not conceivably go along with such a change because they do not take interest in the first place. Only by determining the actions and, in this instance, the vocabulary, of all of the realities, including the Islamic ideal, can the regularizing change be expected to have a receptive audience (Fig. 3). Perhaps more immediately germane to this discussion, the real inheritance of land frequently does not follow the ideal tenure system as defined by society. Were the government to attempt to rationalize and record the actual land-tenure system, without somehow bringing it into congruence with the ideal system, it would face an obstacle to peaceful change that might well thwart its goal.

\section{CONCLUSIONS}

The recent call of researchers in many fields for adaptive research on problems of economic development prompts the analysis of the potential usefulness of an ecologic approach. Unfortunately, within the discipline of geography, ecology has previously been associated with the over-simplified generalizations of the school of environmental determinism. In an over-reaction to this school, geographers have been prone to throw the methodological baby out with the substantive bathwater. The inability of any single discipline to adequately formulate, let alone answer, some of the basic problems of agricultural development suggests a return to a more unified view of man and naturea view provided at least in part by the synthetic concept of ecology.

This paper is not a dogmatic or program- 
matic outline for all future research on such problems, or for all geographers, but what has been identified as cultural ecology provides a potentially powerful and useful amalgam of thought. The investigation of the emergent systems derived from and studied by ecologic analysis can today be reinforced by the theory, methodology, and empirical work of a range of disciplines wider than ever before. It is an accident of history that this overlap today comes in the study of economic development. That specific locus should not be taken as a limiting one when evaluating the overall approach suggested. ${ }^{31}$

In attempting to place this suggested ecologic approach in the perspective of American geographic thought, it is helpful to look to sociology for an analogy. There is little basic disagreement within that discipline on the use of a macro-micro dichotomy when discussing the field in its broadest aspects. No doubt there is internecine warfare on particular issues and priorities of research, but such lack of total harmony within a profession will hardly surprise geographers. ${ }^{32}$ If we attempt to apply a similar sort of classification within geography, those working within the broadly defined area of location theory are, in the terms used here, working in spatial analysis, and, according to the theories they advance, spatial analysis is mostly macrogeography. It is further virtually limited to complex and industrial societies, or those

${ }^{31}$ For a series of studies in which the ecologic approach is either implicitly or explicitly used, see R. W. Kates and I. F. Wohlwill, eds., "Man's Response to the Physical Environment," The Journal of Social Issues, Vol. 22 (1966), pp. 1-140. Of particular interest is the article by J. Wolpert, "Migration as an Adjustment to Environmental Stress," pp. 92-102, an attempt, not wholly successful, to relate ecologic analysis to spatial analysis, although not put in those words by the author.

32 There is, for example, a discussion of "nomothetic macrofunctionalism" by I. Whitaker, "The Nature and Value of Functionalism in Sociology," in D. Martindale, ed., Functionalism in the Social Sciences: The Strength and Limits of Functionalism in Anthropology, Economics, Political Science, and Sociology, Monograph 5 (Philadelphia: The American Academy of Political and Social Science, 1965), p. $139-40$. aspects of other types of societies which are specifically commercial in nature. ${ }^{33}$

We need micro-studies, ecologic studies, to help provide a process-oriented and systemic base for some of these other sorts of work as well as for other purposes. As yet it is difficult, not to say impossible, to relate the tentative theories of spatial studies to ecologic phenomena. This inability, however, hardly need halt research at either level, or the attempt to reconcile the two sometime in the future. Science, or knowledge, if one prefers, proceeds along various fronts, sometimes referred to in the currently popular butcher-shop simile as the "cutting-edges" of research. These points of advance are not arranged along some hierarchical spectrum so that, for example, "micro" is not somehow more basic and "better" than "macro" nor is "macro" somehow broader and "better" than "micro." Neither approach is vaguely more scientific than the other-such a statement is itself antiscientific. Rather, all are aspects of a common attempt to further knowledge-to build tomorrow's explanations upon what was unknown yesterday. The cumulative aspect is essential, not whether it is "micro" or "macro", ecologic or spatial, in conception and application.

${ }^{33}$ A partial exception is the work on agricultural location by M. Chisholm, Rural Settlement and Land Use: An Essay in Location (London: Hutchinson, 1962), particularly Chapter 4, "The Farm and the Village," yet even here the emphasis is not only upon market-oriented farm production but upon Western dry-farming as well. The only land-use factor shared by African and Western cultivators seems to be the factor of labor-those things which require the most intensive care tend to be located nearest the dwellings and, whenever possible, settlements are specifically located to allow for this. In addition to the critical need for ecologic analysis of non-Western agricultural systems, there is an equally critical need for spatial analysis of these systems. It is difficult, for example, to determine the importance of labor, or even to define it economically, in some non-Western situations. Further, how does locational analysis fit with traditional monoculture wet-rice systems? The list of potentially rewarding investigations is almost limitless. Regarding the place of the factor of labor in economic theory, particularly as it relates to "rural underemployment," see Myrdal, op. cit., footnote 29, Part V, "Problems of Labor Utilization," and Appendix 16, "A Critical Appraisal of Selected Studies on 'Unemployment' and 'Underemployment." 